\title{
Transition Metal Complexes of Ligands Containing 3,5-Dimethylpyrazolyl Groups and Thioether Functions. The Crystal and Molecular Structure of (1,12-Bis(3,5-dimethylpyrazol-1-yl)-2,11-diaza-5, 8-dithiadodecane)nickel(II)- bis(tetrafluoroborate)
}

\author{
F. PAAP, W. L. DRIESSEN*, J. REEDIJK \\ Department of Chemistry, Gorlaeus Laboratories, Leiden University, P.O. Box 9502, 2300 RA Leiden, The Netherlands \\ and A. L. SPEK \\ Department of Chemistry, State University Utrecht, Padualaan 8, 3508 TB Utrecht, The Netherlands
}

(Received March 9, 1988)

\begin{abstract}
The hexadentate $\left(\mathrm{N}_{4} \mathrm{~S}_{2}\right)$ ligand 1,12-bis(3,5dimethylpyrazol-1-yl)-2,11-diaza-5,8-dithiadodecane (dsbd) forms compounds $M(d s b d) A_{2}$ where $M$ is Co, $\mathrm{Ni}$ or $\mathrm{Cd}$ and $\mathrm{A}$ is $\mathrm{ClO}_{4}{ }^{-}$or $\mathrm{BF}_{4}{ }^{-}$. The compound $\mathrm{Ni}$ (dsbd) $\left(\mathrm{BF}_{4}\right)_{2}$ crystallizes in the monoclinic space group $P 21 / n, Z=4, a=1.2817(4), b=1.5512(3), c=$ $1.3366(4) \mathrm{nm}, \beta=94.11(1)^{\circ}$. The structure was refined to a final $R_{\mathrm{w}}$ value of 0.032 for $2181 \mathrm{ob}$ served reflections. The nickel ion is octahedrally chelated by two sulfur atoms, two amine nitrogens and two pyrazole nitrogens. $\mathrm{Ni}-\mathrm{N}$ amounts to $210-$ $212 \mathrm{pm}, \mathrm{Ni}-\mathrm{S}$ distances are $243.5 \mathrm{pm}$. The other dsbd compounds have very similar structures as is concluded from their spectroscopic properties. The octadentate $\left(\mathrm{N}_{6} \mathrm{~S}_{2}\right)$ ligand $1,1,10,10$-tetrakis $(3,5$ dimethyl-pyrazol-1-ylmethyl)-1,10-diaza-4,7-dithiadecane (dstd) forms compounds $\mathrm{M}_{2}$ (dstd) $\mathrm{A}_{4}\left(\mathrm{H}_{2} \mathrm{O}\right)_{n}$, where $\mathrm{M}$ is $\mathrm{Mn}, \mathrm{Fe}, \mathrm{Co}, \mathrm{Ni}, \mathrm{Cu}, \mathrm{Zn}$ or $\mathrm{Cd}$; $\mathrm{A}$ is $\mathrm{ClO}_{4}{ }^{-}$ and $n$ is 4 ; where $\mathrm{M}$ is Co, Ni or $\mathrm{Zn}, \mathrm{A}$ is $\mathrm{BF}_{4}^{-}$and $n=$ 4 ; and where $\mathrm{M}$ is $\mathrm{Co}$ or $\mathrm{Ni}, \mathrm{A}$ is NCS $\mathrm{N}^{-}$and $n=0$. In all compounds the metal ions are six-coordinated, as deduced from their spectroscopic properties.
\end{abstract}

\section{Introduction}

Sulfur atoms occur as donor atoms bound to transition metal ions in several metalloenzymes $[1-4]$. To study low-molecular weight models for the active site of this type of metalloenzymes, chelating ligands have been designed which contain thioether or thiolate sulfur atoms in combination with imidazoles $[5-7]$, benzimidazoles $[8,9]$, pyridines $[10]$, pyrazoles [11] and imines [12-14]. These models were synthesized with the aim of obtaining a better insight into the spectroscopic and electrochemical properties and function of the metalloenzymes.

*Author to whom correspondence should be addressed.
Besides biochemical relevance, sulfur-containing chelates with firs-row transition metals are also of more general coordination chemistry interest. The soft character of the sulfur ligand allows investigations concerning the influence upon electronic spectroscopy $[11,15-17]$, the stabilization of low valent oxidation states $[18-20]$, the stereochemical properties $[15-17,21]$ and even the potential application in homogeneous catalysis [19].

With this purpose the ligands 1,12-bis(3,5-dimethylpyrazol-1-yl)-2,11-diaza-5,8-dithiadodecane, abbreviated dsbd, and 1,1,10,10-tetrakis(3,5-dimethylpyrazol-1-ylmethyl)-1,10-diaza-4,7-dithiadecane, abbreviated dstd, were synthesized and their coordination chemistry towards first-row transition metals was investigated. The dsbd ligand combines two thioether sulfur atoms, two secondary amines and two pyrazole rings in a conformation which would allow chelation to one metal ion, thus yielding a potentially hexadentate ligand. The dstd ligand, combining two thioether sulfur atoms, two amine nitrogens and four pyrazole rings, is a potentially octadentate ligand with the possibility of forming dinuclear chelates.

To elucidate the detailed nature of the ligand coordination a crystal structure of a representative compound, viz. $\mathrm{Ni}(\mathrm{dsbd})\left(\mathrm{BF}_{4}\right)_{2}$, has been determined.

\section{Experimental}

\section{Starting Materials}

The solvents, metal salts and their starting reagents were commercially available and used without further purification. Cadmium tetrafluoroborate was prepared in situ by the reaction between cadmium carbonate and tetrafluoroboric acid (30\% in water). Dopes of metals in isomorphous host lattices were prepared by starting from a mixture of the appropriate starting metal salts.

Caution: Several compounds contain perchlorate anions. Although no accidents with perchlorates 
occurred during the experimental work, it is pointed out that the use of perchlorates is hazardous because of the possible explosive nature of these compounds.

\section{Preparation of the Ligands}

Sulfur-containing chelating ligands were prepared from sulfur containing amines. The amine 1,10-diaza4,7-dithiadecane was prepared through the reaction of aziridine with ethylene-1,2-dithiol. The amine was reacted in acetonitrile with four equivalents of 1 hydroxymethyl-3,5-dimethylpyrazole (nhdp) for five days [22]. Evaporation of the solvent yielded the ligand $1,1,10,10$-tetrakis(3,5-dimethylpyrazol-1ylmethyl)-1,10-diaza-4,7-dithiadecane (dstd) as a yellow, viscous liquid. The liquid was washed with a solution of triethylamine in water, after which it solidified within a few days. Recrystallization was effected in diethylether. The ligand was characterized with NMR. The ligand 1,12-bis(3,5-dimethylpyrazol-1-yl)-2,11-diaza-5,8-dithiadodecane (dsdb) was synthesized by the reaction of $0.08 \mathrm{~mol}$ of the amine 1,10-diaza-4,7-dithiadecane with $0.16 \mathrm{~mol}$ nhdp in $400 \mathrm{ml}$ acetonitrile for three days. After evaporation of the solvent the oily liquid was washed with a solution of triethylamine in water, upon which it solidified overnight. The ligand was recrystallized from $3: 1$ mixture of THF and petroleum ether 40-60. NMR spectroscopy, however, indicated the presence of undesired side products (up to $25 \%$ ), but the ligand was nevertheless tried in the synthesis of some coordination compounds.

\section{Coordination Compounds of the Ligands dstd and $d s b d$}

Coordination compounds of formula $\mathrm{M}_{2}$ (dstd) $\mathrm{A}_{4}$ $\left(\mathrm{A}=\mathrm{ClO}_{4}, \mathrm{BF}_{4}\right)$ were synthesized by adding a hot solution of the ligand $(2.5 \mathrm{mmol}$ in $15 \mathrm{ml})$ to a hot solution of the appropriate metal salt $(5.0 \mathrm{mmol}$ in $15 \mathrm{ml}$ ) in ethanol or methanol. The compounds separated from the solution immediately or upon standing overnight. The compounds $\mathrm{M}_{2}$ (dstd)(NCS) 4 $(\mathrm{M}=\mathrm{Co}, \mathrm{Ni})$ were prepared by mixing hot ethanolic solutions of the metal nitrate $(5.0 \mathrm{mmol}$ in $15 \mathrm{ml})$ and the ligand $(2.5 \mathrm{mmol}$ in $15 \mathrm{ml})$, after which a hot solution of $10.0 \mathrm{mmol}$ of $\mathrm{NH}_{4} \mathrm{NCS}$ in $20 \mathrm{ml}$ of a $1: 1$ water-ethanol mixture was added. The compounds separated from the solution upon standing.

The compounds $\mathrm{M}(\mathrm{dsbd})\left(\mathrm{BF}_{4}\right)_{2}$ and $\mathrm{M}(\mathrm{dsbd})$ $\left(\mathrm{ClO}_{4}\right)_{2}(\mathrm{M}=\mathrm{Co}, \mathrm{Ni}, \mathrm{Cd})$ were prepared by adding a solution of $6.5 \mathrm{mmol}$ ligand in $15 \mathrm{mll}$ THF and $15 \mathrm{ml}$ ethanol to a solution of $6.5 \mathrm{mmol}$ of the appropriate metal salt in $10 \mathrm{ml}$ ethanol and $10 \mathrm{ml}$ THF, with $\mathrm{Cd}\left(\mathrm{BF}_{4}\right)_{2}$ being dissolved in $5 \mathrm{ml}$ water and $15 \mathrm{ml}$ ethanol. The compounds separated from the solution upon cooling within a few hours. The compounds were recrystallized from methanol. The compound $\mathrm{Ni}(\mathrm{dsbd})\left(\mathrm{BF}_{4}\right)_{2}$ could also be obtained by reacting dstd $(3.0 \mathrm{mmol}$ in $15 \mathrm{ml})$ with $\mathrm{Ni}\left(\mathrm{BF}_{4}\right)_{2}(6.0 \mathrm{mmol}$ in $15 \mathrm{ml}$ ) in glycolmonomethylether (methyl cellosolve). The compound $\mathrm{Ni}(\mathrm{dsbd})\left(\mathrm{BF}_{4}\right)_{2}$ crystallized from the solution after standing at room temperature for several weeks. When $2.5 \mathrm{mmol} d$ std in $15 \mathrm{ml}$ methanol was reacted with $5.0 \mathrm{mmol} \mathrm{Ni}\left(\mathrm{BF}_{4}\right)_{2}$ in $15 \mathrm{ml}$ methanol a mixture of the blue compound $\mathrm{Ni}_{2}$ (dstd) $\left(\mathrm{BF}_{4}\right)_{4}$ and purple crystals of $\mathrm{Ni}(\mathrm{dsbd})$ $\left(\mathrm{BF}_{4}\right)_{2}$ were formed.

Anal. Found (calc.) for: $\mathrm{Co}_{2}(\mathrm{dstd})\left(\mathrm{ClO}_{4}\right)_{4}\left(\mathrm{H}_{2} \mathrm{O}\right)_{4}$ : C, 30.79 (30.01); H, $4.71(4.70) ; \mathrm{N}, 11.9(11.7) ; \mathrm{Cl}$, 11.6 (11.8); Co, 10.1 (9.8)\%. $\mathrm{Zn}_{2}(\mathrm{dstd})\left(\mathrm{ClO}_{4}\right)_{4}$ $\left(\mathrm{H}_{2} \mathrm{O}\right)_{4}: \mathrm{C}, 28.29$ (29.69); H, $4.19(4.65) ; \mathrm{N}, 10.4$ (11.5); S, 5.1 (5.3); Zn, $11.0(10.8) \% . \mathrm{Ni}_{2}$ (dstd)$(\mathrm{NCS})_{4}\left(\mathrm{H}_{2} \mathrm{O}\right)_{4}$ : C, $39.43(39.47) ; \mathrm{H}, 5.65(5.45) ; \mathrm{N}$, 18.9 (18.9); S, $19.9(18.6)$; Ni, 10.9 (11.3)\%. Ni(dsbd) $\left(\mathrm{BF}_{4}\right)_{2} ; \mathrm{C}, 34.16(34.38) ; \mathrm{H}, 5.14(5.13) ; \mathrm{N}$, $13.3(13.4) ; \mathrm{S}, 10.0(10.2) \% . \mathrm{Co}(\mathrm{dsbd})\left(\mathrm{BF}_{4}\right)_{2}: \mathrm{C}$, 33.88 (34.36); H, 5.02 (5.13); N, 12.0 (13.4); S, 11.2 $(10.2) \% . \mathrm{Cd}(\mathrm{dsbd})\left(\mathrm{BH}_{4}\right)_{2}(\mathrm{MeOH})_{2}: \mathrm{C}, 33.85(32.17)$; $\mathrm{H}, 5.10(5.40) ; \mathrm{N}, 12.8$ (11.3); S, $8.8(8.6) \%$. Cd$(\mathrm{dsbd})\left(\mathrm{ClO}_{4}\right)_{2}(\mathrm{MeOH}): \mathrm{C}, 31.29(30.84) ; \mathrm{H}, 4.84$ (4.90); N, 12.6 (11.4); S, 8.6 (8.7); Cl, $9.4(9.6) \%$.

\section{Spectroscopic and Instrumental Techniques}

IR spectra $\left(4000-180 \mathrm{~cm}^{-1}\right)$ were recorded on a Perkin-Elmer $\mathrm{PE} 380$ instrument, using $\mathrm{KBr}$ pellets and nujol mulls between $\mathrm{NaCl}$ or polyethene discs.

Electronic spectra $(2000-300 \mathrm{~nm})$ were measured on a Perkin-Elmer UV330 instrument, operating in the diffuse reflectance mode with $\mathrm{MgO}$ as a reference.

EPR spectra of powdered samples were measured on a Varian E-3 EPR spectrometer using a $9.5 \mathrm{GHz}$ microwave bridge, at ambient temperature and liquid nitrogen temperature. Spectra could be measured with fields varying between 375 Gauss and 6700 Gauss. Q-band spectra $(35 \mathrm{GHz})$ were measured at room temperature on a Varian E-9, using a Bruker ER 061 SR microwave bridge, at the University of Amsterdam.

NMR spectra were measured in $\mathrm{dmso}^{-\mathrm{d}_{6}}$ solutions. FT NMR spectra were recorded on a Jeol JEC 980B instrument, operating at $50.1 \mathrm{MHz}\left({ }^{13} \mathrm{C}\right)$ and 199.5 $\mathrm{MH}_{z}\left({ }^{\prime} \mathrm{H}\right)$ using ${ }^{2} \mathrm{H}$ as an internal lock. The dmso-d ${ }_{6}$ resonance $\left(39.500 \mathrm{ppm}\left({ }^{13} \mathrm{C}\right)\right.$ or $2.450 \mathrm{ppm}\left({ }^{1} \mathrm{H}\right)$ downfield from TMS) was used as a reference.

Elemental analyses were performed at the Microanalytical Laboratory of the University College, Dublin, Rep. of Ireland.

\section{Crystal Structure Determination}

Purple crystals of $\mathrm{Ni}(\mathrm{dsbd})\left(\mathrm{BF}_{4}\right)_{2}$ could be obtained hy recrystallization of this compound from methanol. Data for a violet transparent crystal, mounted in a Lindemann glass capillary, were collected on an Enraf-Nonius CAD4F diffractometer at ambient temperature. Crystal data and numerical details of the structure determination are given in Table I. Lattice parameters with standard deviations 
TABLE I. Crystal Data and Details of Measurement and Structure Analysis and Refinement of Ni(dsbd)(BF 4$)_{2}$

(a) Crystal data

Formula

Molecular weight

Crystal system

Space group

$a(\mathrm{~nm})$

$b(\mathrm{~nm})$

$c(\mathrm{~nm})$

$\beta\left({ }^{\circ}\right)$

$V\left(\mathrm{~nm}^{3}\right)$

$Z$

$D_{\mathrm{x}}\left(\mathrm{g} \mathrm{cm}^{-3}\right)$

$\mu($ Mo K $\alpha)\left(\mathrm{cm}^{-1}\right)$

$F(000)$

Crystal size (mm)

(b) Data collection

$\theta_{\min }, \theta_{\max }\left({ }^{\circ}\right)$

Radiation (nm)

$\omega / 2 \theta \operatorname{scan}\left({ }^{\circ}\right)$

Hor., vert. aperture, $\left({ }^{\circ}\right)$ dist. to crystal, $(\mathrm{mm})$

Refined reflections (rmsd, \%)

Data set

Total data, unique data

Observed, data $(I>2.5 \sigma(I))$

(c) Refinement

NO, NV

Weighting scheme

$R, R_{\mathrm{w}}, S$

$(\Delta / \sigma)_{\text {av. }}$

Min. and max. resd. $\left(e / \AA^{3}\right)$

\author{
$\mathrm{C}_{18} \mathrm{H}_{32} \mathrm{~B}_{2} \mathrm{~F}_{8} \mathrm{~N}_{6} \mathrm{NiS}_{2}$ \\ 628.90 \\ monoclinic \\ $P 21 / n$ \\ $1.2817(4)$ \\ $1.5512(3)$ \\ $1.3366(4)$ \\ $94.11(1)$ \\ $2.651(1)$ \\ 4 \\ 1.576 \\ 9.6 \\ 1296 \\ $0.20 \times 0.25 \times 0.43$
}

$1.3,22$

Mo $\mathrm{K} \alpha$ ( $\mathrm{Zr}$ filtered), 0.071073

$0.70+0.35 \tan \theta$

$3,3,173$

$\overline{2}, 2, \overline{4}(0.8) ; \overline{3}, 2,7(0.7) ; 4,7, \overline{1}(0.9)$

$h-13: 0 ; k 16: 16 ; l 14: 14$

6849,3244

2181

2181,456

$w=1 / \sigma^{2}(F)$

$0.052,0.032,1.84$

0.1

$0.49,-0.45$ were determined from the setting angles of 23 reflections $\left(8^{\circ}<\theta<12.5^{\circ}\right)$. The observed extinctions $(h 0 l: h+l=2 n+1 ; 0 k 0: k=2 n+1)$ indicated space group $P 2_{1} / n$. Standard deviations in the intensities were increased according to an analysis of the variance of the reference reflections [23]: $\sigma^{2}(I)=$ $\sigma_{\operatorname{cs}}{ }^{2}(I)+(0.008 \times I)^{2}$. The redundant reflection set was corrected for $L p$ and averaged $\left(R_{\mathrm{av}}=0.018\right)$ after correction for absorption with DIFABS [24] (with minimal and maximal correction 0.87 and 1.09). There was no indication for decay during the 101 hours of X-ray exposure time. The structure was solved by direct methods with SHELX84 [25a] and refined with SHELX76 [25b]. Hydrogen atom positions were identified from a difference Fourier map. The tetrafluoroborate anions were found to be disordered and treated with a disorder model including soft bond constraints. Blocked full-matrix refinement on $F$ converged at $R=0.052$. The refined parameters included all positional parameters, anisotropic thermal parameters for the non-hydrogen atoms (except for the fluorine atoms in the minor disorder component with a fixed $U$ of $800 \mathrm{pm}^{2}$ ) and the two isotropic thermal parameters for the hydrogen atoms (one for the methyl group atoms, one for the others). Table II lists the final atomic coordinates for the non-hydrogen atoms. See also 'Supplementary Material'. Scattering factors were taken from Cromer and Liberman [26] and anomalous dispersion terms from Cromer and Mann [27].

\section{Results and Discussion}

Description of the Structure of $\mathrm{Ni}(\mathrm{dsbd})\left(\mathrm{BF}_{4}\right)_{2}$

Relevant bond distances and angles are given in Table III; a drawing of the cation, indicating the used atomic numbering scheme, is shown in Fig. 1. The unit cell contains four $\mathrm{Ni}(\mathrm{d} s \mathrm{dd})^{2+}$ cations and eight disordered $\mathrm{BF}_{4}$ anions that are stacked in alternating layers parallel to the 101 plane.

The central nickel atom is distorted octahedrally surrounded by two cis-positioned sulfur atoms and four nitrogen atoms. The coordination angles deviate from $90^{\circ}$, varying between $85^{\circ}$ and $100^{\circ}$. The nickelsulfur distances of $243 \mathrm{pm}$ are comparable to the 
TABLE II. Fractional Coordinates $\left(\times 10^{5}\right.$ for $\mathrm{Ni}, \times 10^{4}$ for all others) for the Non-hydrogen Atoms of Cation Ni(dsbd) ${ }^{2+}$

\begin{tabular}{lrrr}
\hline Atom & \multicolumn{1}{c}{$x / a$} & \multicolumn{1}{l}{$y / b$} & \multicolumn{1}{l}{ r } \\
\hline $\mathrm{Ni}$ & $19322(6)$ & $19(6)$ & $30184(5)$ \\
$\mathrm{S}(1)$ & $2199(1)$ & $-1423(1)$ & $2317(1)$ \\
$\mathrm{S}(2)$ & $421(1)$ & $-646(1)$ & $3728(1)$ \\
$\mathrm{N}(1)$ & $1189(3)$ & $321(3)$ & $1601(3)$ \\
$\mathrm{N}(2)$ & $2680(4)$ & $-224(3)$ & $4443(3)$ \\
$\mathrm{N}(11)$ & $2927(4)$ & $779(3)$ & $1372(4)$ \\
$\mathrm{N}(12)$ & $3240(4)$ & $368(3)$ & $2242(3)$ \\
$\mathrm{N}(21)$ & $2384(4)$ & $1275(3)$ & $4569(4)$ \\
$\mathrm{N}(22)$ & $1735(4)$ & $1223(3)$ & $3701(3)$ \\
$\mathrm{C}(1)$ & $1828(5)$ & $1008(4)$ & $1196(4)$ \\
$\mathrm{C}(2)$ & $1007(5)$ & $-445(4)$ & $934(4)$ \\
$\mathrm{C}(3)$ & $1869(5)$ & $-1097(4)$ & $1040(5)$ \\
$\mathrm{C}(4)$ & $1085(6)$ & $-2055(4)$ & $2613(5)$ \\
$\mathrm{C}(5)$ & $140(5)$ & $-1583(4)$ & $2945(5)$ \\
$\mathrm{C}(6)$ & $1174(6)$ & $-1129(5)$ & $4776(5)$ \\
$\mathrm{C}(7)$ & $1963(6)$ & $-508(5)$ & $5203(5)$ \\
$\mathrm{C}(8)$ & $3183(5)$ & $610(4)$ & $4738(4)$ \\
$\mathrm{C}(13)$ & $4258(4)$ & $220(4)$ & $2186(4)$ \\
$\mathrm{C}(14)$ & $4593(5)$ & $552(4)$ & $1306(5)$ \\
$\mathrm{C}(15)$ & $3734(5)$ & $883(4)$ & $787(4)$ \\
$\mathrm{C}(16)$ & $4904(5)$ & $-249(5)$ & $2986(5)$ \\
$\mathrm{C}(17)$ & $3597(6)$ & $1326(5)$ & $-211(5)$ \\
$\mathrm{C}(23)$ & $1097(4)$ & $1891(4)$ & $3765(4)$ \\
$\mathrm{C}(24)$ & $1349(5)$ & $2349(4)$ & $4636(5)$ \\
$\mathrm{C}(25)$ & $2163(5)$ & $1939(4)$ & $5146(4)$ \\
$\mathrm{C}(26)$ & $265(5)$ & $2102(4)$ & $2978(5)$ \\
$\mathrm{C}(27)$ & $2717(6)$ & $2121(5)$ & $6138(6)$ \\
\hline & & &
\end{tabular}

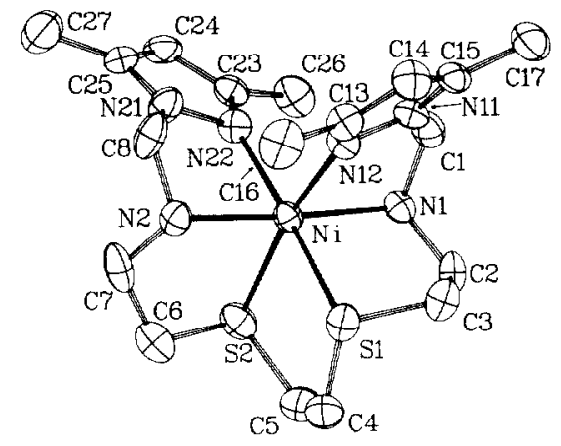

Fig. 1. ORTEP drawing of $\mathrm{Ni}(\mathrm{dsbd})^{2+}$ with used atomic numbering. The arrow indicates the pseudo $C_{2}$ axis. $40 \%$ probability ellipsoids. Hydrogen atoms not shown.

distance of $246 \mathrm{pm}$ reported for $\mathrm{Ni}(\mathrm{daes})_{2}\left(\mathrm{ClO}_{4}\right)_{2}$ [28], which has cis-positioned sulfur atoms trans to amine nitrogen atoms in the compound $\mathrm{Ni}(\mathrm{L}) \mathrm{Br}^{+}[27]$ ( $\mathrm{L}=1,11$-dimino-1,6,9-trithiaundecane). The $\mathrm{Ni}-\mathrm{N}$ (pyrazole) bonds are 211 and $213 \mathrm{pm}$, and agree very well with the distance of $214 \mathrm{pm}$ found in $\mathrm{Ni}$ (debd). $\left(\mathrm{N}_{3}\right)_{2}$ [29]. The $\mathrm{Ni} \mathrm{N}($ amine) distances have values comparable to similar compounds $[28,30]$.

The coordination configuration around the nickel is of approximate $C_{2}$ symmetry, but the folding of the ligand chain around the metal center is highly irregular. This can be seen from the torsion angles (Table III), which differ up to $110^{\circ}$ from the approximate two fold axial symmetry. The torsion angles

TABLE III. Relevant Bond Lengths (pm), Bond Angles $\left({ }^{\circ}\right)$ and Torsion Angles of Ni(dsbd) $\left(\mathrm{BF}_{4}\right)_{2}$

Within the coordination sphere

$\begin{array}{ll}\mathrm{Ni}-\mathrm{S}(1) & 243.5(2) \\ \mathrm{Ni}-\mathrm{S}(2) & 243.4(2) \\ \mathrm{Ni}-\mathrm{N}(1) & 211.7(4) \\ \mathrm{Ni}-\mathrm{N}(2) & 209.9(4) \\ \mathrm{Ni}-\mathrm{N}(12) & 211.1(5) \\ \mathrm{Ni}-\mathrm{N}(22) & 212.5(5)\end{array}$

Within the dsbd ligand

$\begin{array}{ll}\mathrm{S}(1)-\mathrm{C}(3) & 180.1(7) \\ \mathrm{S}(1)-\mathrm{C}(4) & 179.9(7) \\ \mathrm{S}(2)-\mathrm{C}(5) & 181.2(7) \\ \mathrm{S}(2)-\mathrm{C}(6) & 180.6(7) \\ \mathrm{N}(1)-\mathrm{C}(2) & 149.4(7) \\ \mathrm{N}(2)-\mathrm{C}(7) & 148.5(9) \\ \mathrm{N}(2)-\mathrm{C}(8) & 148.6(8) \\ \mathrm{N}(11)-\mathrm{N}(12) & 136.1(7) \\ \mathrm{N}(11)-\mathrm{C}(1) & 145.5(8) \\ \mathrm{N}(11)-\mathrm{C}(15) & 135.0(8) \\ \mathrm{N}(12)-\mathrm{C}(13) & 133.2(7) \\ \mathrm{N}(21)-\mathrm{N}(22) & 138.1(7) \\ \mathrm{N}(21)-\mathrm{C}(8) & 146.0(8)\end{array}$

$\mathrm{S}(1)-\mathrm{Ni}-\mathrm{S}(2)$
$\mathrm{S}(1)-\mathrm{Ni}-\mathrm{N}(1)$
$\mathrm{S}(1)-\mathrm{Ni}-\mathrm{N}(2)$
$\mathrm{S}(1)-\mathrm{Ni}-\mathrm{N}(12)$
$\mathrm{S}(1)-\mathrm{Ni}-\mathrm{N}(22)$
$\mathrm{S}(2)-\mathrm{Ni}-\mathrm{N}(1)$
$\mathrm{S}(2)-\mathrm{Ni}-\mathrm{N}(2)$
$\mathrm{S}(2)-\mathrm{Ni}-\mathrm{N}(12)$

$\mathrm{Ni}-\mathrm{S}(1)-\mathrm{C}(3)$

$\mathrm{Ni}-\mathrm{S}(1)-\mathrm{C}(4)$

$\mathrm{Ni}-\mathrm{N}(12)-\mathrm{C}(13)$

$\mathrm{N}(11)-\mathrm{N}(12)-\mathrm{C}(13)$

$\mathrm{N}(22)-\mathrm{N}(21)-\mathrm{C}(8)$

$\mathrm{N}(22)-\mathrm{N}(21)-\mathrm{C}(25)$

$\mathrm{C}(8)-\mathrm{N}(21)-\mathrm{C}(25)$

$\mathrm{Ni}-\mathrm{N}(22)-\mathrm{N}(21)$

$\mathrm{Ni}-\mathrm{N}(22)-\mathrm{C}(23)$

$\mathrm{N}(21)-\mathrm{N}(22)-\mathrm{C}(23)$

$\mathrm{N}(1)-\mathrm{C}(1)-\mathrm{N}(11)$

$\mathrm{N}(1)-\mathrm{C}(2)-\mathrm{C}(3)$

$S(1)-C(3)-C(2)$

$85.00(6)$
$86.2(1)$
$97.5(1)$
$85.2(1)$
$177.1(1)$
$97.2(1)$
$84.4(1)$
$169.9(1)$

$\mathrm{S}(2)-\mathrm{Ni}-\mathrm{N}(22)$
$\mathrm{N}(1)-\mathrm{Ni}-\mathrm{N}(2)$
$\mathrm{N}(1)-\mathrm{Ni}-\mathrm{N}(12)$
$\mathrm{N}(1)-\mathrm{Ni}-\mathrm{N}(22)$
$\mathrm{N}(2)-\mathrm{Ni}-\mathrm{N}(12)$
$\mathrm{N}(2)-\mathrm{Ni}-\mathrm{N}(22)$
$\mathrm{N}(12)-\mathrm{Ni}-\mathrm{N}(22)$

94.5(1)

$176.1(2)$

$79.6(2)$

$96.7(2)$

99.4(2)

$79.6(2)$

$95.4(2)$

$94.6(2)$
$105.9(2)$
$142.8(4)$
$105.2(4)$
$117.5(5)$
$113.1(5)$
$129.4(5)$
$109.3(3)$
$144.8(4)$
$103.7(4)$
$108.8(5)$
$113.5(5)$
$113.6(4)$
$112.9(3)$

115.1(4) $113.9(4)$

$110.8(5)$

$118.4(5)$

$111.1(5)$

$130.5(5)$

$110.5(4)$

$122.6(5)$

$127.0(5)$

$106.6(5)$

$106.6(5)$

(continued)
$104.9(3)$ 
TABLE III. (continued)

Within the dsbd ligand

$\begin{array}{ll}\mathrm{N}(21)-\mathrm{C}(25) & 132.9(8) \\ \mathrm{C}(2)-\mathrm{C}(3) & 149.7(9) \\ \mathrm{C}(4)-\mathrm{C}(5) & 151(1) \\ \mathrm{C}(6)-\mathrm{C}(7) & 148(1) \\ \mathrm{C}(13)-\mathrm{C}(14) & 138.0(9) \\ \mathrm{C}(13)-\mathrm{C}(16) & 149.4(9) \\ \mathrm{C}(14)-\mathrm{C}(15) & 135.9(9) \\ \mathrm{C}(15)-\mathrm{C}(17) & 150.0(9) \\ \mathrm{C}(23)-\mathrm{C}(24) & 138.2(9) \\ \mathrm{C}(23)-\mathrm{C}(26) & 148.0(8) \\ \mathrm{C}(24)-\mathrm{C}(25) & 136.2(9)\end{array}$

Torsion angles

$\begin{array}{lr}\mathrm{S}(1)-\mathrm{C}(4)-\mathrm{C}(5)-\mathrm{S}(2) & -37.0(7) \\ \mathrm{C}(3)-\mathrm{S}(1)-\mathrm{C}(4)-\mathrm{C}(5) & -83.2(5) \\ \mathrm{C}(4)-\mathrm{C}(5)-\mathrm{S}(2)-\mathrm{C}(6) & -59.6(5) \\ \mathrm{C}(2)-\mathrm{C}(3)-\mathrm{S}(1)-\mathrm{C}(4) & 70.8(5) \\ \mathrm{C}(5)-\mathrm{S}(2)-\mathrm{C}(6)-\mathrm{C}(7) & 147.9(5) \\ \mathrm{N}(1)-\mathrm{C}(2)-\mathrm{C}(3)-\mathrm{S}(1) & 51.9(6) \\ \mathrm{N}(2)-\mathrm{C}(7)-\mathrm{C}(6)-\mathrm{S}(2) & -58.5(7) \\ \mathrm{C}(1)-\mathrm{N}(1)-\mathrm{C}(2)-\mathrm{C}(3) & 85.1(6) \\ \mathrm{C}(6)-\mathrm{C}(7)-\mathrm{N}(2)-\mathrm{C}(8) & 158.6(6) \\ \mathrm{N}(11)-\mathrm{C}(1)-\mathrm{N}(1)-\mathrm{C}(2) & -81.5(5) \\ \mathrm{C}(7)-\mathrm{N}(2)-\mathrm{C}(8)-\mathrm{N}(21) & -73.9(6) \\ \mathrm{N}(2)-\mathrm{C}(8)-\mathrm{N}(21)-\mathrm{N}(22) & -42.0(6) \\ \mathrm{N}(1)-\mathrm{C}(1)-\mathrm{N}(11)-\mathrm{N}(12) & -36.6(6)\end{array}$

$\begin{array}{rll}117.8(4) & \mathrm{N}(11)-\mathrm{C}(15)-\mathrm{C}(17) & 121.6(6) \\ 115.4(5) & \mathrm{C}(14)-\mathrm{C}(15)-\mathrm{C}(17) & 131.8(6) \\ 110.0(5) & \mathrm{N}(22)-\mathrm{C}(23)-\mathrm{C}(24) & 110.4(5) \\ 111.6(5) & \mathrm{N}(22)-\mathrm{C}(23)-\mathrm{C}(26) & 122.9(5) \\ 106.7(5) & \mathrm{C}(24)-\mathrm{C}(23)-\mathrm{C}(26) & 126.7(6) \\ 110.4(5) & \mathrm{C}(23)-\mathrm{C}(24)-\mathrm{C}(25) & 107.8(5) \\ 103.0(3) & \mathrm{N}(21)-\mathrm{C}(25)-\mathrm{C}(24) & 105.0(5) \\ 103.7(2) & \mathrm{N}(21)-\mathrm{C}(25)-\mathrm{C}(27) & 123.8(6) \\ 94.4(2) & \mathrm{C}(24)-\mathrm{C}(25)-\mathrm{C}(27) & 131.1(6)\end{array}$

$100.9(3)$

$105.8(3)$

$\mathrm{Ni}-\mathrm{N}(1)-\mathrm{C}(1)$

about $\mathrm{C}(2)-\mathrm{C}(3)$ and $\mathrm{C}(6)-\mathrm{C}(7)$ have comparable absolute values but opposite signs. Both $\mathrm{N}(1)-\mathrm{H}$ and $\mathrm{N}(2)-\mathrm{H}$ are hydrogen bonded to $\mathrm{F}$ atoms of the disordered $\mathrm{BF}_{4}{ }^{-}$anions $(\mathrm{N}(1) \cdots \mathrm{F}(12)=2.917(8) \mathrm{pm}$, $\mathrm{N}(2) \ldots \mathrm{F}(22)=301.6(7) \mathrm{pm}, \mathrm{N}(2) \ldots \mathrm{F}(23)=326.1$ (7) $\mathrm{pm}$ ).

Description of the dsbd Compounds; Infrared Spectra The six metal-dsbd complexes $\mathbf{M}(\mathrm{dsbd}) \mathrm{A}_{2}(\mathbf{M}=$ $\mathrm{Co}, \mathrm{Ni}, \mathrm{Cd} ; \mathrm{A}=\mathrm{ClO}_{4}, \mathrm{BF}_{4}$ ) have very similar IR spectra, indicating very similar ligand conformations. The only significant differences are concerned with the $\mathrm{BF}_{4}$ and $\mathrm{ClO}_{4}$ vibrations. It can be concluded that all dsbd compounds have a six-coordinated structure, similar to the structure of $\mathrm{Ni}(\mathrm{dsbd})\left(\mathrm{BF}_{4}\right)_{2}$.

\section{Description of the dstd Compounds; Infrared Spectra}

The dstd compounds with the metal perchlorates of $\mathrm{Mn}, \mathrm{Fe}, \mathrm{Co}, \mathrm{Ni}, \mathrm{Cu}, \mathrm{Zn}$ and $\mathrm{Cd}$ all show similar infrared spectra, indicating a similar ligand conformation. The tetrafluoroborate compounds of the metals $\mathrm{Co}, \mathrm{Ni}$ and $\mathrm{Zn}$ show only differences with respect to the perchlorate vibrations. The ligand conformation is probably very similar to the conformation in the perchlorate compounds. The coordination of water molecules is indicated by a strong absorption in the region of $3500 \mathrm{~cm}^{-1}$. A dinuclear structure for the dstd compounds can be proposed with the metal coordinated by two pyrazoles, an amine nitrogen and a sulfur from the dstd ligand, with two water mole cules completing the octahedral coordination.

The infrared spectra of the compounds $\mathrm{Ni}_{2}$ (dstd)$(\mathrm{NCS})_{4}$ and $\mathrm{Co}_{2}(\mathrm{dstd})(\mathrm{NCS})_{4}$ are very similar to one another, and only show small differences with the spectra of the perchlorate compounds. The NCS vibrations are split, indicating a cis-arrangement of thiocyanate ligands [31]. These compounds probably have structures comparable to the structure of the perchlorate compounds, with thiocyanates being coordinated instead of the water molecules in the perchlorate compounds.

\section{NIR - Vis spectroscopic properties of the dsbd compounds}

Spectroscopic data are given in Table IV. The perchlorate and tetrafluoroborate compounds of the same metal have identical NIR-Vis spectra, indicating a negligible influence of the anions upon the metal-dsbd coordination unit.

The cobalt and nickel compounds show typical octahedral ligand field spectra. The $D q$ parameters are in agreement with an $\mathrm{N}_{4} \mathrm{~S}_{2}$ chromophore [32].

The lowest energy band of the nickel compounds is split into two components. This is probably due to a close approach and subsequent mixing of the spinallowed ${ }^{3} \mathrm{~A}_{2 \mathrm{~g}}-{ }^{3} \mathrm{~T}_{2 \mathrm{~g}}$ transition with the forbidden 
TABLE IV. Electronic Transitions of dstd and dsbd Compounds ${ }^{a}$

\begin{tabular}{|c|c|c|c|c|}
\hline Compound & $\sigma_{1}$ & $a_{2}$ & $\sigma_{3}$ & Other \\
\hline $\mathrm{Co}(\mathrm{dsbd})\left(\mathrm{ClO}_{4}\right)_{2}$ & 9.16 & 17.9 & 20.9 & 29.9 \\
\hline $\mathrm{Co}(\mathrm{dsbd})\left(\mathrm{BF}_{4}\right)_{2}$ & 9.16 & 17.9 & 21.1 & 29.1 \\
\hline $\mathrm{Co}_{2}(\mathrm{dstd})\left(\mathrm{H}_{2} \mathrm{O}\right)_{4}\left(\mathrm{ClO}_{4}\right)_{4}$ & 8.77 & 15.6 & 20.0 & 32.2 \\
\hline $\mathrm{Co}_{2}(\mathrm{dstd})\left(\mathrm{H}_{2} \mathrm{O}\right)_{4}\left(\mathrm{BF}_{4}\right)_{4}$ & 9.11 & 15.6 & 19.6 & 32.1 \\
\hline $\mathrm{Co}_{2}(\mathrm{dstd})(\mathrm{NCS})_{4}$ & 7.04 & & 18.2 & 28.6 \\
\hline $\mathrm{Ni}(\mathrm{dsbd})\left(\mathrm{ClO}_{4}\right)_{2}$ & $10.00 ; 11.4$ & 18.1 & 28.3 & \\
\hline $\mathrm{Ni}(\mathrm{d} s \mathrm{bd})\left(\mathrm{BF}_{4}\right)_{2}$ & $9.90 ; 11.4$ & 18.1 & 27.9 & \\
\hline $\mathrm{Ni}_{2}$ (dstd $)\left(\mathrm{H}_{2} \mathrm{O}\right)_{4}\left(\mathrm{ClO}_{4}\right)_{4}$ & 9.85 & 15.9 & 26.3 & \\
\hline $\mathrm{Ni}_{2}(\mathrm{dstd})\left(\mathrm{H}_{2} \mathrm{O}\right)_{4}\left(\mathrm{BF}_{4}\right)_{4}$ & 9.80 & 15.4 & 26.5 & \\
\hline $\mathrm{Ni}_{2}(\mathrm{dstd})(\mathrm{NCS})_{4}$ & 9.58 & 16.9 & 26.2 & \\
\hline $\mathrm{Cu}_{2}(\mathrm{dstd})\left(\mathrm{H}_{2} \mathrm{O}\right)_{4}\left(\mathrm{ClO}_{4}\right)_{4}$ & \multicolumn{3}{|c|}{13.6 shoulder at $c a .10$} & 28.7 \\
\hline
\end{tabular}

a Values in $10^{3} \mathrm{~cm}^{-1}$.

${ }^{3} \mathrm{~A}_{2 \mathrm{~g}}{ }^{-1} \mathrm{E}_{\mathrm{g}}$ transition [28]. Taking this into account, the spectra can be fitted with $D q$ and $B$ values of 1050 and $935 \mathrm{~cm}^{-1}(\beta=\mathrm{B}: \mathrm{Bo}=0.90)$ respectively, which agrees with the values for the cobalt compounds (1000 and $870 \mathrm{~cm}^{-1}(\beta=0.90)$ respectively.) The observed splitting does not seem to be the consequence of a lowering of the symmetry by the cispositioned sulfur ligands. The splitting of the second absorption band, expected in such cases [32] is not observed, nor is there any indication for a lowering of symmetry in the spectra of the cobalt compounds. The lowering of symmetry does not cause a splitting of absorption bands, but leads to the unusually high value for the ligand field parameter $B$, calculated for these compounds.

The high-energy transition in the spectra of the cobalt compounds can be assigned to a $\mathrm{S}-\mathrm{Co}$ chargetransfer transition $[32,33]$, confirming the presence of a $\mathrm{Co}-\mathrm{S}$ coordination bond.

\section{NIR - Vis Spectroscopic Properties of the dstd Compounds}

As can be seen from Table IV, the data for the perchlorate and tetrafluoroborate compounds are nearly identical, indicating a negligible influence of the anion variation upon the metal coordination unit. The spectra of the $\mathrm{Ni}$ and Co fluoroborate and perchlorate compounds are in agrecment with the proposed octahedral structure. The $D q\left(995 \mathrm{~cm}^{-1}\right.$ for $\mathrm{Co}, 980 \mathrm{~cm}^{-1}$ for $\left.\mathrm{Ni}\right)$ and $B$ values $\left(775 \mathrm{~cm}^{-1}\right.$ for $\mathrm{Co}$, $830 \mathrm{~cm}^{-1}$ for $\mathrm{Ni}$ ) are in agreement with an $\mathrm{N}_{3} \mathrm{SO}_{2}$ chromophore [32]. The high-energy transition in the spectra of the cobalt compounds can be compared to the transition found in the dsbd compounds, which was assigned to a $\mathrm{S}-\mathrm{Co}$ charge-transfer transition, and can be taken as an indication for the presence of a Co-S coordination bond $[32,33]$.

Like in the cobalt compounds, a high-energy transition is also found in the electronic spectrum of the $\mathrm{Cu}$ compound, which can be assigned to a $\mathrm{S}-\mathrm{Cu}$ charge-transfer transition $[32,7]$.
The compounds $\mathrm{Ni}_{2}(\mathrm{dstd})(\mathrm{NCS})_{4}$ and $\mathrm{Co}(\mathrm{dstd})$. $(\mathrm{NCS})_{2}$ show spectra indicative of highly distorted structures. This distortion is probably due to a change in coordination environment. Probably the $\mathrm{M}-\mathrm{S}$ distance becomes semi-coordinating upon coordination of the stronger thiocyanate ligands.

\section{EPR Spectroscopy}

The spectrum of the copper compound shows a ligand field transition, which is in agreement with the proposed octahedral coordination [34]. The Q-band EPR spectrum shows a rhombic spectrum, with three $g$ values $(2.27,2.07,2.05)$, in agreement with the proposed structure, with cis-coordinated oxygen atoms. The highest $g$ value, with a linewidth of 380 Gauss, does not show hyperfine coupling.

\section{NMR Spectroscopy}

The zinc and cadmium compounds were sufficiently soluble in dmso to allow NMR spectra to be recorded. The data are listed in Table $\mathrm{V}$. The spectra of the two dsbd compounds are essentially the same, confirming the structural similarity.

In the proton spectrum, the protons of the pyrazoles and the methyl groups are observed as single sharp resonances, which is to be expected from the approximate $C_{2}$ symmetry of the ligand. The protons $\mathrm{C} 7, \mathrm{C} 2$ and $\mathrm{C} 3, \mathrm{C} 6$ are observed as a complicated multiplet comparable to the free ligand. The protons on $\mathrm{C} 4$ and $\mathrm{C} 5$ occur as a broad multiplet, centered at $2.32 \mathrm{ppm}$. The sharp singlet, observed in the free ligand is effectively split due to coordination of the sulfur atoms. The protons on $\mathrm{C} 1$ and $\mathrm{C} 8$ are observed as a sharp resonance, indicative of a fast exchange process. The amine protons are observed as a broad resonance of low intensity at $11.9 \mathrm{ppm}$.

The NMR spectra of the dstd compounds are comparable to the spectra of the dsbd compounds. As the sulfur atoms in the dstd compounds are coordinating to different metal ions, and not chelating like the sulfur atoms in the dsbd compounds, the rotation 
TABLE V. NMR $\left({ }^{1} \mathrm{H}\right.$ and $\left.{ }^{13} \mathrm{C}\right)$ Data of dstd and dsbd Compound $\mathrm{s}^{\mathrm{a}}$

\begin{tabular}{|c|c|c|c|c|c|c|c|c|c|c|}
\hline $\begin{array}{l}\text { Carbon } \\
\text { Compound }\end{array}$ & 4 & 3 & 5 & 1,8 & 2,7 & 3,6 & 4,5 & $\mathrm{~N}-\mathrm{H}$ & 7 & 6 \\
\hline dsbd & 5.81 & & & 4.88 & 2.71 & & 2.62 & & 2.33 & 2.27 \\
\hline $\mathrm{Cd}(\mathrm{dsbd})\left(\mathrm{BF}_{4}\right)_{2}$ & 5.81 & & & 4.88 & 2.77 & & 2.32 & 11.9 & 2.18 & 2.07 \\
\hline $\mathrm{Cd}(\mathrm{dsbd})\left(\mathrm{ClO}_{4}\right)_{2}$ & 5.80 & & & 4.86 & 2.69 & & 2.30 & 11.9 & 2.16 & 2.06 \\
\hline dstd & 5.82 & & & 4.91 & 2.73 & 2.35 & 2.46 & & 2.22 & 2.10 \\
\hline $\mathrm{Zn}_{2}$ (dstd $)\left(\mathrm{ClO}_{4}\right)_{4}$ & 5.81 & & & 4.87 & 2.69 & 2.30 & 2.40 & & 2.17 & 2.06 \\
\hline $\mathrm{Cd}_{2}(\mathrm{dstd})\left(\mathrm{ClO}_{4}\right)_{4}$ & 5.81 & & & 4.87 & 2.69 & 2.30 & 2.40 & & 2.17 & 2.06 \\
\hline dsbd & 106.0 & 139.7 & 146.6 & 65.3 & 49.2 & 28.1 & 31.0 & & 13.5 & 10.6 \\
\hline $\mathrm{Cd}(\mathrm{dsbd})\left(\mathrm{BF}_{4}\right)_{2}$ & 105.5 & 139.5 & 146.1 & 64.8 & 49.0 & 28.4 & 31.0 & & 13.4 & 10.6 \\
\hline $\mathrm{Cd}(\mathrm{dsbd})\left(\mathrm{ClO}_{4}\right)_{2}$ & 104.9 & 138.9 & 145.5 & 64.3 & 48.5 & 27.9 & 30.6 & & 12.8 & 10.0 \\
\hline dstd & 105.4 & 139.3 & 146.0 & 64.8 & 49.0 & 28.4 & 31.0 & & 13.3 & 10.5 \\
\hline $\mathrm{Zn}_{2}(\mathrm{dstd})\left(\mathrm{ClO}_{4}\right)_{4}$ & 106.9 & 141.1 & 147.2 & 64.9 & 49.9 & 26.6 & 31.6 & & 13.8 & 10.8 \\
\hline $\mathrm{Zn}_{2}$ (dstd)(BF$)_{4}$ & 106.3 & 140.4 & 147.3 & 64.7 & 49.5 & 27.9 & 31.3 & & 13.5 & 10.7 \\
\hline $\mathrm{Cd}_{2}(\mathrm{dstd})\left(\mathrm{ClO}_{4}\right)_{4}$ & 106.2 & 140.6 & 147.2 & 64.9 & 49.4 & 28.2 & 31.4 & & 13.6 & 10.8 \\
\hline
\end{tabular}

${ }^{a}$ Numbering as in Fig. 1.

about the $\mathrm{C} 4-\mathrm{C} 5$ bond is not restrained, and the protons on these carbon atoms appear as a sharp resonance.

\section{Conclusions}

The ligand dsbd acts as a hexadentate ligand towards the divalent metals cobalt, nickel and cadmium, combining thioether, amine and pyrazolenitrogen donor atoms within one ligand. The ligand imposes a distorted octahedral coordination geometry upon the metal, as can be seen from the structure of $\mathrm{Ni}(\mathrm{dsbd})\left(\mathrm{BF}_{4}\right)_{2}$. The sulfur coordination, proven by the crystal structure, is also observed from the occurrence of a $\mathbf{S}$-Co charge-transfer transition in the cobalt compounds, and by the NMR data of the cadinium compounds.

The ligand dstd acts as an octadentate, dinucleating ligand towards the metals manganese, iron, cobalt, nickel, copper, zinc and cadmium, as concluded from analytical and spectroscopic data. Infrared data in combination with elemental analyses agree with the dinucleating nature of the ligand. NIR-Vis spectra indicate the octadentate nature of the ligand, and $S-M$ charge-transfer transitions, observed with the metals cobalt and copper, confirm the sulfur coordination. The similarity in the infrared spectra make sulfur coordination plausible in all perchlorate and tetrafluoroborate compounds. However, in the nickel-thiocyanate and cobalt-thiocyanate compounds, probably the sulfur coordination is weaker because of the influence of the strong NCS ligand.

\section{Supplementary Material}

Lists of the thermal parameters and of the observed and calculated structure factors are available from author A.L.S. on request.

\section{Acknowledgements}

The authors wish to thank Dr B. P. van Eijck for collecting the diffraction data. The investigations were supported in part (A.L.S.) by the Netherlands Foundation for Chemical Research (SON) with financial aid from the Netherlands Organization for Research (NWO).

\section{References}

1 E. T. Adam, R. E. Stenkamp, L. C. Sieker and L. H. Jensen, J. Mol. Biol., 125, 35 (1978).

2 H. Eklund, B. Nordstrom, E. Zeppezauer, G. Soderlund, I. Ohlsson, T. Boiwe, B. O. Soderbers, O. Tapia, C. I. Branden and A. Akeson, J. Mol. Biol., 102, 27 (1976).

3 M. H. Frey, G. Wagner, M. Vasak, O. W. Srenson, D. Neuhaus, E. Wörgötter, J. H. R. Kägi, R. R. Ernst and K. Wüthrich, J. Am. Chem. Soc., 107, 6847 (1985).

4 M. C. Feiters, Ph.D. Thesis, State University of Utrecht, 1984.

5 J. van Rijn, W. L. Driessen, J. Reedijk and J. M. Lehn, Inorg. Chem., 23, 3584 (1984).

$6 \mathrm{~W}$. H. Armstrong, M. T. Youinou, R. E. Palermo and R. H. Holm, Inorg. Chim. Acta, 88, 21 (1984).

7 N. F. Aoi, G. Matsubyashi and T. Tanaka, J. Chem. Soc., Dalton Trans., 1059 (1983).

8 A. W. Addison, P. J. Burke, K. Henrich, T. N. Rao and E. Sinn, Inorg. Chem., 22, 3645 (1983). 
9 J. M. Latour, D. Limosin and P. Rey, J. Chem. Soc., Chem. Commun., 464 (1985).

10 K. D. Karlin and J. K. Yandell, Inorg. Chem., 23, 1184 (1984).

11 M. DiVaira and F. Mani, J. Chem. Soc., Dalton Trans., 2327 (1985).

12 A. W. Addison, T. N. Rao and E. Sinn, Inorg. Chem., 23, 1957 (1984).

13 N. F. Aoi, G. Matsubayashi and T. Tanaka, Inorg. Chim. Acta, 114, 25 (1986).

14 O. P. Anderson, J. Becher, H. Frydendahl, L. F. Taylor and H. Toftlund, J. Chem. Soc., Chem. Commun., 699 (1986).

15 J. C. A. Boeyens, S. M. Dobson and R. D. Hancock, Inorg. Chem., 24, 3073 (1985).

16 M. J. Bjerrum, T. Laier and E. Larsen, Inorg. Chem., 25, $816(1986)$

17 G. R. Brubaker, M. G. Henk and D. W. Johnson, Inorg. Chim. Acta, 100, 201 (1985).

18 L. R. Gahan, G. A. Lawrence and A. M. Sargeson, Inorg. Chem., 23, 4369 (1984).

19 J. A. R. Hartman, E. J. Hintsa and S. R. Cooper, J. Am Chem. Soc., 103, 1208 (1986).

20 J. A. R. Hartman and S. R. Copper, J. Am. Chem. Soc., 108,1202 (1986).

21 G. Baumann, L. G. Marzilli, C. L. Nix, Il, and B. Rubin, Inorg. Chim. Acta, 77, L35 (1983).
22 W. L. Driessen, Recl. Trav. Chim. Pays-Bas, 10I, 441 (1982).

23 L. E. McCandlish, C. H. Stout and L. C. Andrews, Acta Crystallogr., Sect. A, 31, 245 (1975).

24 N. Walker and D. Stuart, Acta Crystallogr., Sect. A, 39, 158 (1983).

25 (a) G. M. Sheldrick, 'SHELX84', University of Göttingen, 1984; (b) 'SHELX76', University of Cambridge, 1976.

26 D. T. Cromer and D. Liberman, J. Chem. Phys., 53, 1891 (1970).

27 D. T. Cromer and J. B. Mann, Acta Crystallogr., Sect. A, 24, 321 (1968).

28 S. M. Hart, J. C. A. Boeyens and R. D. Hancock, Inorg. Chem., 22, 982 (1983).

29 F. Paap, W. L. Driessen, J. Reedijk, B. Kojic-Prodic and A. L. Spek, Inorg. Chim. Acta, 104, 55 (1985).

30 M. G. B. Drew, D. A. Kice and K. M. Richards, J. Chem. Soc., Dalton Trans., 2382 (1976).

31 K. Nakamoto, 'Infrared and Raman Spectra of Inorganic and Coordination Compounds', 3rd edn., Wiley-Interscience, New York, 1978.

32 A. B. P. Lever, 'Inorganic Electronic Spectroscopy', 2nd edn., Elsevier, Amsterdam, 1984.

33 J. S. Thompson, T. N. Sorrell, T. J. Marks and J. A. Ibers, J. Am. Chem. Soc., 101, 4180 (1979).

34 B. J. Hathaway and D. E. Billing, Coord. Chem. Rey., 5, 143 (1970). 